\title{
DOCÊNCIA EM FILOSOFIA: PENSANDO NA PRÁTICA
}

\author{
Wilson Francisco Correia*
}

\begin{abstract}
RESUMO
Este trabalho enfoca a temática pertinente ao ensino de Filosofia pelo viés do exercício docente. Problematiza a prática de ensino de conteúdos filosóficos. Foi realizado sob as diretrizes da pesquisa filosófica. Baseouse na literatura especializada da área, com foco naqueles trabalhos que abordam a problemática do ensino de Filosofia na Educação Básica. Propõe indicações para debate sobre a necessidade de se superar o cânone tradicional de pesquisa e ensino no âmbito do saber filosófico.

Palavras-chave: Filosofia. Ensino. Prática.

ABSTRACT

This work focuses on the theme relevant to the teaching of Philosophy by the bias of the teaching exercise. It questions the practice of teaching of philosophical content. Was performed under the guidelines of philosophical inquiry. Based on the literature of the area, focusing on those works that address the problem of teaching Philosophy in Education. Proposed indications for debate on the need to overcome the traditional canon of research and teaching in the context of philosophical knowledge.
\end{abstract}

Keywords: Philosophy. Education. Practice.

\section{Introdução}

Podemos dizer que "docência" é um termo que tem a ver com a capacidade do profissional do magistério de propor e vivenciar experiências concretas de ensino e aprendizagem. Segundo o dicionário, "docente"

\footnotetext{
* Doutor em Educação pela Universidade de Campinas (UNICAMP). Professor Adjunto da Universidade Federal do Recôncavo da Bahia (UFRB) e do Centro de Formação de Professores (CFP), em Amargosa, BA. E-mail: correia.wilson@yahoo.com.br
} 
nomeia quem ensina e "diz respeito a professores. Do latim docens, docentis, particípio presente de docere, 'ensinar"' (FERREIRA, 1975, p. 274).

"Filosofia" pode ser compreendida como exercício do pensamento, no sentido daquela prática na qual "cada sujeito" estabelece "relação própria com o pensar", na "possibilidade de formação e transformação do que se é" (LARROSA, 1998, p. 24). Relaciona-se ao campo conceitual dos saberes e da pesquisa que abordam a condição humana no mundo, entre tantos outros assuntos, fazendo-o sob o viés da formação de estilos existenciais para o homem e a mulher, além de enfocar o modelo societário desejável para o ser humano.

Nessa perspectiva, o presente estudo manifesta o entendimento de que a famosa questão hegelo-kantiana (RAMOS, 2007) ainda está posta à nossa apreciação: ensina-se filosofia, como propôs Hegel, ou, como defendeu Kant, ensina-se a filosofar, excetuando-se o ensino da história da filosofia? [Ipsis literis: "Entre todas as ciências racionais (a priori) só é possível, por conseguinte, aprender a matemática, mas nunca a filosofia (a não ser historicamente): quanto ao que respeita à razão, apenas se pode, no máximo, aprender a filosofar" (KANT, 1989, p. 660)].

Hoje, dadas as contribuições teóricas sobre a estilística pedagógica que se presta a sustentar a prática docente no âmbito da filosofia, talvez esse dilema possa ser considerado superado. Professores de Filosofia se valem de variadas obras produzidas na área para trabalhar informações, conhecimentos e saberes de natureza filosófica e, ao mesmo tempo, também instigam ao filosofar, sendo que até a história da filosofia pode instigar à produção filosófica autoral, dado que são inúmeras as portas possíveis à experiência e ao exercício do pensamento.

Se considerarmos o filosofar como prática de uma estilística atitudinal, mas que vai além do estilo, o tratamento didático-pedagógico bibliográfico reservado aos clássicos originais e às obras introdutórias, histórias e especializadas pode ser considerado o eixo teórico-metodológico central no desenvolvimento do processo de ensino e aprendizagem em filosofia. Ademais, esse tratamento pode ser entendido como um caminho deveras profícuo para a proposição da experiência do exercício do pensamento, na busca da autoria mesma por parte de estudantes e de professores na área da filosofia (PALÁCIOS, 1997). 
Para tanto, inspirados em Cabrera (2010, p. 32-33), entendemos ser crucial o enfrentamento do desafio que é o de ir além do cânone tradicional, o mais encontradiço entre nós sobre a produção e ensino filosóficos, qual seja: 1. Adoção de problemas objetivamente elaborados na pesquisa em filosofia e que se encontrem filiados à tradição filosófica clássica, e só a ela circunscritos; 2. Emprego de regras de metodologia científica que possibilitem o tratamento rigoroso, claro e preciso dos conceitos filosóficos, quase sempre tomados como pontos de partida, invés de serem buscados como pontos de chegada; 3 . Pudor esmerado na materialização bibliográfica de autores compreendidos como autoridades na tradição filosófica, sempre pela via de citações e referências documentalmente exatas, quase sempre queridas em suas línguas originais.

Pensando nessa perspectiva, este trabalho observa esses problemas em sua organização, além das questões cotidianas que pedem pesquisas, debates e até mesmo pronunciamentos e propositura de solução. Nem sempre essas respostas são possíveis. Porém, no propósito de compartilhar e socializar os resultados da busca investigativa, o presente texto dedicase, em um primeiro momento, a pensar sobre a docência em filosofia. Detém-se na didática filosófica, plausível quando se fala em docência no âmbito da área filosófica. Por fim, este texto aborda questões relativas ao interpretar, comentar e refletir, e o faz mediante o esforço para ir além da mera reprodução conceitual, estendida aos estudantes de filosofia.

\section{Da docência em filosofia}

A profissão docente exige domínio teórico, metodológico e ético (CORREIA, 2006). Assim, não basta apenas saber teoria e nem tão-só como proceder metodológica e tecnicamente em situações de ensino e aprendizagem. De pouco adianta, ainda, agir visando ao que o ensinante considera bem ético, desconsiderando a teoria filosófica e a metodologia de ensino dada pela pedagogia. Integrar o saber teórico, a metodologia, a técnica, a política e a ética parece ser fundamental no exercício do magistério em filosofia, sob pena de se deixar a desejar nos processos implicados na experiência de pensamento em filosofia. Vários são as informações, conhecimentos e saberes que podem e devem ser mobilizados 
pelo professor para compor o próprio perfil profissiográfico ao ensinar Filosofia (GAUTHIER, 1998).

O professor que procura formar-se continuamente na perspectiva de adquirir saber teórico, saber fazer e saber ético extrai seus instrumentos profissionais da vida particular na família, no trabalho e em outros espaços da convivência social. Ao que parece, a educação pessoal tem implicação direta na formação profissional docente e isso apresenta relevante influência no modo como o profissional do magistério se desincumbe de suas tarefas (TARDIF; RAYMOND, 2000).

Ele aproveita, também, as informações e os conhecimentos aos quais teve acesso ao longo de sua educação formal em nível fundamental, médio e universitário, bem como os da socialização pré-profissional, não relegando ao segundo plano as vivências reais em todos esses processos (TARDIF; RAYMOND, 2000). E o desafio aí é o de realizar a integração entre teoria e prática, se não satisfatoriamente nos períodos de estágio, continuamente nas etapas de inserção na prática do magistério.

Além dessas aquisições simbólicas, o profissional do magistério dedicado ao ensino da Filosofia pode e deve se valer do uso dos saberes da tradição filosófica e da tradição pedagógica, tanto quanto dos conhecimentos curriculares voltados especialmente para a formação docente. Nesse sentido, a leitura dos clássicos poderá ser auxiliada por obras de caráter didático, tais como as introdutórias, as históricas, as especializadas, como dissertações e teses, sem contar a produção diuturna e ininterruptamente publicada sobre a filosofia e seu ensino.

O professor de filosofia que julga de somenos a articulação consistente desses saberes pode incorrer na atitude antipedagógica e antididática reveladora do entendimento de que apenas o domínio específico da filosofia basta à prática do ensino. O que estou argumentando é que não basta apenas teoria, isolada de outros saberes, pelo fato de o exercício do ato de ensinar exigir o saber fazer metodológico e o saber ético relativo ao ser-estar humano entre humanos (GAUTHIER, 1998). Por isso, a velha separação entre bacharelado e licenciatura historicamente verificada nos cursos de graduação no Brasil precisa ser revista, como, no caso específico da formação de professores de filosofia, também precisa ser revisto o distanciamento entre filosofia e pedagogia. A primeira parece não prescindir da segunda. 
Ademais, pode o professor complementar os saberes anteriormente registrados com aqueles encontrados nos livros introdutórios, históricos, especializados e, sobretudo, nos clássicos originais da filosofia, como já foi assinalado, lançando mão da variedade de materiais conforme a necessidade dos estudantes. Se assim o fizer, saberes experienciais, específicos do quefazer docente e inerentes à ação pedagógica em filosofia serão imensamente enriquecidos e constantemente atualizados. Basta interessarse e realizar. O que me parece exagero é a atitude de desconsiderar os materiais produzidos hodiernamente no âmbito da pesquisa e da didática filosófica em nome de um apego cego aos clássicos. Até a ida aos clássicos precisa ser pedagogicamente orientada, sob pena do fracasso estudantil.

Nessa perspectiva, então, o professor de filosofia é chamado a:

a) adotar uma perspectiva filosófica, entre as muitas existentes, e explicitá-la para os estudantes;

b) evitar a transposição pedagógica linear e sem problematização das linhas, correntes e escolas de pensamento, evitando tomá-las como dadas e acabadas, mas, sim, propondo a criação filosófico-conceitual;

c) compor o próprio perfil profissiográfico visando a deter amplo domínio da história da filosofia, mantendo a atitude de filósofo;

d) saber articular as ciências, a filosofia e as artes para enriquecer o material de ensino e estudo;

e) deter técnicas de estudo de textos filosóficos que vão além da mera interpretação, do simples comentário e da reflexão pela mera reflexão $\mathrm{e}$

f) lançar mão de técnicas de escrita, de expressão do próprio pensamento, visando a obter mais um instrumento a ser utilizado na mediação entre os estudantes e os temas da filosofia.

\section{A didática da filosofia}

A didática da filosofia implica o entendimento sobre a atividade de submeter os conhecimentos originariamente produzidos no campo da investigação filosófica a tratamentos apropriados para que se tornem ensináveis em contextos reais de ensino e aprendizagem em nosso sistema educacional. Isso significa que os vários saberes curriculares devem ser 
recodificados para habitarem a sala de aula, de maneira que os estudantes possam lidar com eles visando ao próprio aprendizado, potencializador do desenvolvimento biológico, psíquico, cognitivo, cultural e social no qual se encontram ao longo da existência (REBOUL, 1974).

Nesse sentido, entre os diversos fatores possivelmente relacionáveis com os materiais a serem empregados no ensino de filosofia, o professor talvez possa atentar para:

a) A contexto mais amplo em que apareceram na história o autor e a obra estudada: a história, a cultura e a sociedade em suas dimensões econômica, política e ideológica, objetiva e subjetivamente circunstanciados.

b) Os elementos epistêmicos afins e correlatos à obra explorada: os saberes curriculizados e considerados válidos, bem como aqueles que não logram aceitação curricular, em meio aos quais a Filosofia se apresenta, atentando para a multiplicidade dos saberes correlatos à filosofia, o que se torna uma exigência da prática de seu ensino.

c) Os aspectos éticos que atravessam a obra em exame: os princípios, os valores, as normas e as regras morais que os seres humanos legitimam e que comparecem no processo da educação formal, tanto quanto as práticas éticas oficialmente renegadas, mas afetas às obras estudadas.

d) Os fatores humanos implícitos na relação pedagógica: o professor e o aluno em situações concretas de ensino e aprendizagem, ao lado dos demais profissionais atuantes no campo da educação escolar, tanto quanto a comunidade de que a escola faz parte.

e) Os aspectos didático-metodológicos e técnicos necessários à compreensão do que se estuda: os procedimentos específicos de ensino e aprendizagem, tomados como caminho capaz de conduzir o professor ao êxito na docência e o aluno ao aprendizado significativo.

Como é possível notar em todo esse contexto, surge relevante a figura do professor, profissionalmente compreendido. Ele é o sujeito social que, ao exercer a profissão, constrói elos entre educação e mundo, vida e escola, saber vivido pelo aluno e conhecimentos a serem apreendidos nos tempos e espaços da instituição de ensino.

Nesse sentido, se bem compreendida, e não considerada como algo de somenos em relação ao saber filosófico, a didática, como arte de ensinar, 
pode contribuir para que o professor de filosofia tenha em seu trabalho um quefazer que transcenda métodos e técnicas que não primem pela liberdade de ensinar e aprender. Ela pode contribuir para a construção de uma identidade profissional em articulação com os processos de significação da vida e do mundo, possibilitando a gestão da sala de aula sob a ótica de uma ética relacional fundada no gosto pela conquista do saber.

\section{Sobre o interpretar, o comentar e o refletir}

Lidando diariamente com questões relativas ao "fazer" e ao "ensinar" filosofia em nosso sistema de ensino, sobretudo o superior ou universitário, deparo, todos os dias, com a "teoria do basta". Para os adeptos dessa teoria, raramente explicitada, o entendimento é o de que para fazer e ensinar filosofia "basta interpretar", "basta comentar", "basta refletir". Mas... será que a "teoria do basta" é suficiente?

\subsection{Sobre a interpretação}

No âmbito da "interpretação", vejo e ouço pessoas inteligentes dizendo; "Neste trecho, nesta obra, neste trabalho... o autor $\mathrm{X}$ quis dizer Y". Aí o interpretador, ainda que técnicas apuradas garantam a interpretação semântica e literária rigorosa do escrito, arroga-se o direito de dizer o que o "outro quis dizer", intermediando o autor original e os estudantes que intentam estudar as ideias desse autor X. É o interpretador querendo-se a si próprio onisciente, qual uma entidade divina que detém o sentido e o significado do conteúdo escrito pelo autor $\mathrm{X}$, abominando qualquer outro entendimento possível a respeito da matéria analisada. Muitas vezes esse interpretador apropria-se do discurso e faz dele um instrumento para defender ideias que não estão na intenção do autor original. Um exemplo disso é certo tratamento dado a Epicuro (2002), quase sempre denunciado como hedonista, e só, ao passo que sabemos que o que Epicuro propõe não cabe em tamanho reducionismo. Problematizo, neste parágrafo, a falta de zelo no trabalho de compreender o autor para sobre ele opinar, bem como as distorções cotidianamente vistas sobre os originais estudados. 
Ora, somente uma pessoa no mundo pode dizer com segurança o que alguém "quis dizer", quando a interpretação transcende o tratamento técnico, semântico e filosófico apropriado: o próprio autor do trecho, da obra e do trabalho estudado, feitos, evidentemente, de conceitos os quais toda pessoa de inteligência mediana pode explorar para compreender por conta própria e com honestidade intelectual, não necessitando de um atravessador iluminado para "traduzir acrescentando" o pensamento do clássico levado a exame. Como, geralmente, esse autor X aí é um morto, então essa tentativa do interpretador que "personaliza a obra filosófica" não passa de usurpação e charlatanismo filosóficos. O respeito sagrado à intenção e ao dito do autor original é imprescindível.

Isso de tentar interpretar, nos moldes acima mencionados, é fazer filosofia? Essa prática deve merecer gasto de energia em situações reais de ensino e aprendizagem em nosso sistema educacional brasileiro? Talvez fosse mais produtivo que nos ativéssemos à busca por nós mesmos, com honestidade intelectual perante os autores estudados e com o propósito de formar pessoas que pensem por conta própria e com o imprescindível auxílio dos clássicos.

\subsection{Sobre o comentário}

Quando deparo com o "comentário", às vezes e em alguns casos, irmão gêmeo ou mesmo filho legítimo da interpretação, a prática segue um pouco aquilo que afirmou Whitehead (apud PORTNOY, 1980, p. 191), de que "O desenvolvimento da filosofia ocidental tem sido uma mera adição de notas de rodapé à filosofia de Platão". Aí o comentador vai além do "interpretar idiossincratizando" e intenta "explicar" o original, valendo-se da forma do comentário. Ele chega ao cúmulo de dividir o indivisível: "O primeiro Marx, o segundo Marx", por exemplo, como se o autor "explicado" não tivesse o direito, neste caso, de modificar o próprio pensamento, sendo cindido em si mesmo, feito dois autores diferentes, e não um sujeito social que produziu e modificou (para melhor ou para pior) o próprio pensamento.

Estranho demais! Comentar é fazer filosofia? Talvez, longe disso, seja um subterfúgio para não se pensar concretamente sobre os problemas atuais que nos afligem. 
Os clássicos originais fizeram filosofia porque debruçaram sobre os problemas de sua época, os quais tiveram facetas diferentes daquelas que os mesmos problemas apresentam em nossos dias, precisando ser enfrentados por vivos e não por pensamentos de mortos que já vieram ao mundo e deram suas inegáveis contribuições. Lê-los e usá-los para compreender a história atual, sim; repeti-los, de modo pessoal, em intermináveis comentários que tentam esclarecer a outrem o que os clássicos quiseram dizer, não! (PALÁCIOS, 1997).

Mas ... tem gente que casa com Platão, Aristóteles, conforme o gosto. E não apenas casa, mas se torna escravo do dito do grego, do morto, do gênio que veio antes e pensou, sem o mínimo esforço para ir além deles. Aí a verdade: se ser escravo de vivo já é absurdo, imagine ser escravo de um morto? O pior é fazer-se escravo do morto não porque o morto o quis, mas por livre e espontânea adesão, como bem alertou La Boetie (1982) em seu famoso e atualíssimo Discurso da servidão voluntária. Só mesmo uma mente altamente perturbada se sujeitaria desse modo a algo e a alguém de maneira tão despersonalizante.

\subsection{Sobre a reflexão}

Parece óbvio que interpretação e comentário são operações cognitivas e discursivas feitas por quem lida com o fazer e o ensinar filosofia, tomando-os como tarefas que se prestam à "reflexão" filosófica, esse conhecido ouroboros verborrágico de quem fica circulando em torno do pensamento já pensado, sem dar azo a que o novo, o inusitado e o vira-ser possam ser produzidos e nos servir de apoio para a solução de nossos problemas atuais, surgidos na atualidade.

Os alunos de nossas academias sabem muito bem disso: interpretam, comentam e refletem porque, do contrário, estarão irremediavelmente perdidos. Ai deles se ousarem pensar por conta própria! "Repitam, reproduzam, infinitamente, e tudo estará em paz", parece ser o imperativo que não deixa escapatória para quem quer que seja. Nesse aspecto, os exemplos diários são incontáveis quando o assunto é interpretar, comentar e refletir de maneira forçada por uma prática pedagógica que inibe e tolhe a liberdade de pensar e expressar o próprio pensamento por parte de nossos estudantes. 
Então, se está decidido, de antemão, que aprender e fazer filosofia são sinônimos de interpretar, comentar e refletir, com os regimes de verdade preditando as ações (FOUCAULT, 2004), sem vislumbrar a possibilidade de criação e invenção, a produção inovadora não terá lugar em nossas salas de aula, práticas de pesquisa e extensão; em nossos trabalhos acadêmicos e em nossas produções docentes e discentes. Basta, aí, a reprodução pela reprodução refletidora e tudo estará em paz nos círculos formais de educação.

Refletir é fazer filosofia? Cá entre nós: haverá pior filosofia do que essa que "reflete" em vez de provocar o novo de nossa produção? Até quando vamos nos contentar com as soluções alienígenas que transplantamos em nossas reflexões para, com elas, tentar resolver problemas que são específicos e nascidos de nossa realidade brasileira em sua ampla complexidade? Como já foi dito, a filosofia "não é reflexão, porque ninguém precisa de filosofia para refletir sobre o que quer que seja" (DELEUZE; GUATTARI, 1992, p. 14).

\section{Conclusão}

Fazer transposição pedagógica, então, não significa cair no tecnicismo da esmiuçassão conceitual, nem se identifica com essa prática de reflexão que não sai do lugar. Também não tem nada a ver com a repetição ou reprodução interminável do pensamento de outrem, mas com o pensar por conta própria, com o trabalho de procurar por si mesmo e com a decisão de assumir a autoria do próprio modo de pensar e de se expressar.

O desafio aí é o de que temos uma produção consagrada (clássica) e que ela deve ser estudada, mas de maneira que nos faça compreender a vida atual, a educação de nossos dias, a sociedade de hoje e a história que estamos fazendo. A erudição pela erudição não faz o menor sentido. O que dá significado ao nosso quefazer é a prática de utilizar os instrumentos da filosofia para pensarmos os problemas que batem às nossas portas.

Sem compreender a nossa própria vida, pouco ou quase nada de sentido existencial poderá qualificar a nossa breve passagem pela Terra, muito menos poderá dar sentido à educabilidade que tanto valorizamos. E, ao que me parece, um currículo de formação filosófica que segue esse norte da criação, sem se contentar com a mera repetição coloca-se no bom caminho. 
Além disso, resumindo o que tentei dizer desde o início neste trabalho, penso que aprender, ensinar e fazer filosofia é possível, desde que os professores de filosofia de todos os níveis da educação formal:

1. Deixemos claro para os alunos que as práticas de aprender, ensinar e fazer filosofia exigem que ousemos ir além da hermenêutica e da exegese dos meros comentários, das distorcidas interpretações e das repetidas reflexões que tentam explicar o já originariamente explicado pelo próprio autor do texto filosófico, dedicando-nos ao estudo analítico e conceitual consequente em nossas salas de aula.

2. Entendamos que concordar ou discordar, o modo mais indicado de fazer filosofia, só é possível se elaboramos a defesa das teses que nos garantem em um sentido ou noutro e o façamos de maneira clara, concisa e objetiva, cuidando para que as razões das verdades defendidas possam ser compreendidas por outrem.

3. Esforcemo-nos para ler o texto filosófico de maneira que trabalhe para compreender o discurso como se o lêssemos com os olhos do próprio autor, pois para concordar ou discordar precisamos, antes, compreender, sob pena de distorcermos as ideias e os conceitos estudados. Primeiro a compreensão, depois a opinião.

4. Que, antes da memorização, retenção e mimetismo repetidor, os professores de filosofia criemos condições de trabalho filosófico para os alunos de modo que privilegie a produção criativa e criadora, com vistas para o enfrentamento dos problemas atuais que nos afetam, e não apenas o mergulho em preciosismos de erudição sobre o já vivido e já pensado.

5. Saibamos que ensinar e aprender filosofia, utilizando obras introdutórias, históricas, especializadas e originais são práticas que requerem entendamos que a abordagem filosófica das coisas pode se dar pela via histórica, problematizadora e temática, e não somente como história unívoca e linear que envolvem autores, obras, linhas e correntes filosóficas.

6. Superemos as dicotomias entre licenciatura e bacharelado e o distanciamento entre filosofia e pedagogia, pois o ensinar e o aprender a fazer filosofia exigem que lancemos mão de informações, conhecimentos e saberes produzidos nas áreas que pensam sobre o processo da educabilidade humana, com especificidade e com recursos que a filosofia sozinha não possui. 
7. Tomemos a iniciativa de levar a público o que produzimos a título de saber filosófico em nossas academias, não temendo o debate que deve motivar o ensinar, o aprender e o fazer filosofia, passando ao largo, quando necessário, das exigências tecnicistas e quantitativistas dos órgãos oficiais que acabam por promover uma prática de pesquisa em filosofia ao molde do ermitão solitário e que não dialoga com ninguém.

8. Trabalhemos para desmistificar o ensino de filosofia, evitando tratá-lo como assunto de iniciados, hermeticamente dirigido a gênios ou às mentes especiais, mas, privilegiando a comunicação, lançando mão de informações introdutórias, históricas e especializadas no trabalho de conduzir o processo de ensino e aprendizagem em filosofia. A motivação para filosofar reside nos mais variados lugares e, privilegiadamente, nas próprias pessoas.

9. Valorizemos o entendimento de que todo autor escreve para ser compreendido e que explicações e "leituras" (leitura nietzscheana sobre Sócrates, por exemplo), muitas vezes, produzem confusão em vez de compreensão, pois, baseados na "igualdade das inteligências" (RANCIÈRE, 2002), os clássicos não precisam de atravessadores idiossincráticos interpostos entre eles (clássicos) e nossos estudantes.

10. Visemos à superação demétodos de produção filosófica assentada em formas de fazer filosofia herdadas do tomismo, do estruturalismo e do positivismo, por exemplo, promovendo novas concepções metodológicas que privilegiem, não a mera reflexão ou a linearidade na produção, mas o novo e a criação filosófico-conceitual.

A cada homem e a cada mulher cabe o desafio do tempo vivido no presente. Que o passado possa ser visto como aquele mestre que nos dá as lições e nos instiga a vivê-las por nossa própria conta. Viver enterrado no passado ou apenas no sonho da vida futura são apenas modos de deixar de viver, pois é o presente o que pede a nossa pertença.

\section{Referências}

PALÁCIOS, G. A. De como fazer filosofia sem ser grego, estar morto ou ser gênio. Goiânia: UFG, 1997.

CABRERA, J. Ousadia de pensar. In: . Filosofia. ano IV, 52. ed. Out. São Paulo: Escala, 2010. p. 30-37 
CORREIA, W. Saber ensinar. São Paulo: EPU, 2006.

. Três teses sobre a docência. Revista Espaço Acadêmico. n. 97, Junho, 2009. Maringá: UEM, Disponível em: <http://periodicos.uem.br/ ojs/index.php/EspacoAcademico/ article/viewFile/7112/4137>. Acesso em: 30 Mar. 2011.

DELEUZE, G.; GUATTARI, F. O que é a filosofia? Tradução de B. Prado. Júnior; A. A. Muñoz. Rio de Janeiro: 34, 1992.

EPICURO. Carta sobre a felicidade: a Meneceu. Tradução e apresentação de Á. Lorencine; E. Del Carrote. São Paulo: Editora Unesp, 2002.

FERREIRA, A. B. H. Novo dicionário da língua portuguesa. Rio de Janeiro: Nova Fronteira, 1975.

FOUCAULT, M. Verdade e poder. In: Microfísica do poder. Rio de Janeiro: Graal, 2004.

GAUTHIER, C. Por uma teoria pedagógica. Juí: Unijuí, 1998.

KANT, I. Crítica da razão pura. 2. ed. Lisboa: Calouste Gulbenkian, 1989.

LA BOETIE, E. D. Discurso da servidão voluntária. Tradução de L. G. dos Santos. São Paulo: Brasiliense, 1982.

LARROSA, J. La experiencia de la lectura: estúdios sobre literatura e formacion. Barcelona: Editorial Laertes, 1998.

PORTNOY, J. The philosopher and music: a historical outline. New York: Da Capo Press, 1980.

RAMOS, C. A. Aprender a filosofar ou aprender a filosofia: Kant ou Hegel? Trans/Form/Ação, São Paulo, v. 30, n. 2, p. 197-217. 2007.

RANCIÈRE, J. $O$ mestre ignorante: cinco lições sobre a emancipação intelectual. Tradução de L. do Valle. Belo Horizonte: Autêntica, 2002.

REBOUL, O. Filosofia da educação. São Paulo: Companhia Editora Nacional, 1974.

TARDIF, M.; RAYMOND, D. Saberes, tempo e aprendizagem do trabalho no magistério. Educação \& Sociedade, Campinas, n. 73, p. 209-244, 2000.

Data de registro:23/04/2012

Data de aceite:03/10/2012 